\title{
Phylogenetic Analysis And Searching Bovine Papillomaviruses In Teat Papillomatosis Cases In Cattle By Histopathological, Immunohistochemical And Transmission Electron Microscopy Methods
}

Yakup Yıldırım ( $\nabla$ yayildirim@hotmail.com )

Burdur Mehmet Akif Ersoy University https://orcid.org/0000-0003-4299-4712

Mehmet Kale

Burdur Mehmet Akif Ersoy University

Özlem Özmen

Burdur Mehmet Akif Ersoy University

Abdurrahman Anıl Çağırgan

Izmir/Bornova Veterinary Control Institute

Sibel Hasırcıoğlu

Burdur Mehmet Akif Ersoy University

Ali Küçük

Burdur Mehmet Akif Ersoy University

Ayşegül Usta

Burdur Mehmet Akif Ersoy University

Sevinç Sökel

Burdur Mehmet Akif Ersoy University

\section{Research Article}

Keywords: Bovine papillomavirus, Cattle, Histopathology, Immunohistochemistry, Phylogeny,

Transmission Electron Microscopy

Posted Date: December 15th, 2021

DOI: https://doi.org/10.21203/rs.3.rs-1032786/v2

License: (9) (1) This work is licensed under a Creative Commons Attribution 4.0 International License.

Read Full License 


\section{Abstract}

Papillomaviruses are epitheliotropic viruses causing proliferations in skin, mucosa and various internal organs in different animal species. Especially due to lesions it causes in teats of cattle, it leads to important economical losses in milk sector. In this study, the aim was to diagnose bovine papillomaviruses (BPVs) causing teat papillomas in cattle by immunohistochemical, transmission electron microscopy (TEM) and molecular methods and to detect the defect on tissues by the virus using histopathological method. In addition to this, sequence analysis of the isolated field strains were to be carried out and their genetic and phylogenetic closeness with the strains within the literature were to be detected. After confirming teat papillomatosis in the collected samples using histopathological and immunohistochemical methods, other diagnosis methods were then used. During the TEM examination of teat lesions, intranuclear virus particles were seen in epithelium cells. After carrying out PCR using degenerate primers and type specific primers, 7 samples were detected as positive for BPV and these samples were used for typing using sequence analysis/PCR with type-specific primers. Within these analysis, three out of seven BPV isolates we collected from infected teat tissues of different cattle were detected as BPV-6, two as BPV-10, one as BPV-2 and one as BPV-8. Five isolates we isolated during sequence analysis of positive samples were found in Xipapillomavirus 1 genus, one in Epsilonpapillomavirus 1 genus and another in Deltapapillomavirus genus. As a result, in molecular diagnosis of BPV that takes place in etiology of teat papillomas, using type specific primers proved to be useful following the usage of genotyping in molecular diagnosis of BPV and generate primers in characterization. Detecting BPV types and their prevalence, taking biosafety measures in animal breeding and giving importance to vaccine studies was considered essential.

\section{Introduction}

Papillomaviruses are viral agents causing lesions characterized by mucosal and cutaneous proliferations, papillomas, fibropapillomas and neoplasias in various animal species (Araldi et al. 2017; MacLachlan et al. 2017). It is an agent type specific causing benign tumoral formations mostly within squamous epithelium layer. However, in some studies, bovine papillomavirus-1 (BPV-1) and BPV-2 were detected in different equidae species (Ugochukwu et al. 2019). The agent, which has a non-membraneous and icosahedral structure, carries a dsDNA genome with a length of nearly 8000 bp (Daudt et al. 2019). Three different regions are located on the viral genome as Early (E), Late (L) and Long Codon Region (LCR) (MacLachlan et al. 2017). E region codes proteins (E1, E2 and E4) and oncoproteins (E5, E6 and E7) that play a role in replication stage and $L$ region is responsible for coding capsid proteins (L1 and L2) (Dörttaş and Dağalp 2020). LCR region does not code any protein whereas it takes part in starting the viral replication (Araldi et al. 2017). BPVs are classified based on the genomic regions of the L1 ORF, the most conserved region (Dağalp et al. 2017). The virus types infecting animals are found within 32 different genus located in papillomaviridae family. Twentynine types of BPV are currently well characterized; 26 of them are grouped into five genera, with three types still unclassified. The Deltapapillomavirus has four types (BPV-1, -2, -13, and -14). Dyokappapapillomavirus has three types 
(BPV-16, -18 and -22). The Xipapillomavirus genus has two species: Xipapillomavirus 1 (BPV-3, -4, -6, -9, $-10,-11,-15,-17,-20,-23,-24,-26,-28$ and -29) and Xipapillomavirus 2 (BPV-12). The other two genus are Epsilonpapillomavirus 1 (BPV-5, -8 and -25) and Dyoxypapillomavirus 1 (BPV-7) (Borzacchiello and Roperto 2008; Lunardi et al. 2013; Daudt et al. 2018; Walker et al. 2019; Papillomavirus Episteme 2021).

The virus is mostly contaminated by direct contact, however, factors such as contaminated foods and equipments and iatrogenic errors causes the agent to transmit via indirect horizontal way (MacLachlan et al. 2017; Ugochukwu et al. 2019). Cutaneous lesions caused by the agent might have different morphologies such as filiform, peduncle, atypical or squamous papillomas (Lunardi et al. 2013; Daudt et al. 2018). Lesions are frequently observed on head, neck, back areas, udder and teat base and in abdomen. In addition, BPV types causing carcinomas are also observed in genital and gastrointestinal channel mucosas and vesica urinaria (Borzacchiello and Roperto 2008; Roperto et al. 2013; Lunardi et al. 2013). The most isolated papillomavirus types in teat papillomatosis cases are BPV-1, -2 (Deltapapillomavirus), BPV-6, -9, -10 (Xipapillomavirus), BPV-7 (Dyoxypapillomavirus), BPV-5 and BPV-8 (Epsilonpapillomavirus) (Campo 2002; Lunardi et al. 2013). The diagnosis of BPV infection can mostly be done by clinical or histopathological examination (Dörttaş and Dağalp 2020). In addition, transmission electron microscopy (TEM) and immune histochemical analysis are successful methods commonly used in diagnosis (Catroxo et al. 2013). PCR technique, which has a high specifity and sensitivity, is also frequently used in molecular detection of the agent and taxonomy studies (MacLachlan et al. 2017; Dörttaş and Dağalp 2020). In addition to autohemotherapy and surgical attempts, many methods such as antibiotics, chemotherapeutic, immune modulator and antiparasitary drug applications have been tried in bovine papillomatosis treatment. Besides, there also studies in which the effectiveness of autologous and cell culture vaccines is searched (Ugochukwu et al. 2019; Dörttaş and Dağalp 2020).

In this study, the aim was to diagnose BPV which causes teat papillomas in cattle by immune histochemical, transmission electron microscopy and molecular methods and to detect the defect on tissues by the virus using the histopathological method. Additionally, sequence analysis of the isolated field strains was carried out and their genetic and phylogenetic closeness with the strains in the literature was desired to be detected.

\section{Materials And Methods}

\section{Sampling animals and clinical samples}

Tissue (papilloma) samples were collected from 7 holstein female cows (aged between $3.81 \pm 1.38$ on average (2-8 years of age) with different shaped lesions on their udder (flat and round, rice grain, cauliflower and filiform). Papilloma tissue samples that broke during the examination with palpation and then ligatured with sterile silk thread and removed by the help of a scalpel were brought into the diagnosis laboratory in collection boxes according to cold chain protocol. 
The samples were kept in $-20^{\circ} \mathrm{C}$ deep freezer until used in molecular studies. Additionally, the other samples taken from the same tissue underwent pre-treatments without being frozen to be used in histopathology, immunohistochemistry and electron microscopy applications.

\section{PCR, sequencing and phylogenetic analysis}

DNA extraction from papilloma lesions was performed using DNeasy Blood \&Tissue Kit (Qiagen, Germany). The extraction process was carried out according to the protocol stated by the producing company. The obtained DNA extracts were kept in $-20^{\circ} \mathrm{C}$ deep freezer. Gene specific degenerate primers FAP59 / FAP64 (FW 5'-TAACWGTIGGICAYCCWTATT-3'; Rev 5'-CCWATATCWVHCCATITCICCATC-3') and MY09 / MY11 (FW 5'-GCMCCMARRGGAWACTGATC-3'; Rev 5'-CGTCCMARRGGAWACTGATC-3') coding the conserved L1 ORF region to detect BPV types in a wide range were used (Silva et al. 2016). For this purpose, a PCR mixture was prepared using Taq DNA polymerase $25 \mathrm{U} / \mathrm{ml}, 200 \mu \mathrm{M}$ dATP, $200 \mu \mathrm{M}$ dGTP, $200 \mu \mathrm{M}$ dCTP, $200 \mu \mathrm{M}$ dTTP, $1,5 \mathrm{mM} \mathrm{MgCl}_{2}$ and $0.25 \mu \mathrm{M}$ of each oligonucleotide primer. $23 \mu \mathrm{l}$ was taken from this mixture for each sample and $2 \mu \mathrm{l}$ DNA extract was added onto it and the reaction volume was completed to $25 \mu$ l. Later, DNA fragments were amplified according to the method stated by Silva et al. (2016). Amplicons were monitored under UV light using \%1,5 Tris Asetat Buffer (TAE) agarose gel electrophoresis and Safe View ${ }^{\text {TM }}$ (abm, Cat No: G108) stain. The samples whose BPV presence was molecularly detected by degenerate primers were later amplified using type specific primers. For this purpose, the PCR mixture was reprepared using type specific primers rather than using PCR mixture FAP59/FAP64 and MY09/MY11 oligonucleotides used during the amplification stage performed by consensus primers and $25 \mu \mathrm{l}$ reaction volume was created. DNA templates were amplified according to the method specified by Silva et al. (2016) using the primer sequences indicated in Table 1. The amplicons were monitored under UV light using \%2 tris acetate buffer (TAE) agarose gel elektrophoresis and Safe View ${ }^{\mathrm{TM}}$ (abm, Cat No: G108) stain (Silva et al. 2016).

The PCR products were sequenced with both forward and reverse primer by a Microsynth AG (Balgach, Switzerland). Nucleotide sequence results were analyzed using DNADynamo DNA Sequence Analysis Software. To compare the similarities of consensus nucleotide sequences the Basic Local Alignment Search Tool (BLAST) software of the National Center for Biotechnology Information (NCBI) was used (Altschul et al. 1990). For phylogenetic analysis of the partial L1 gene region targeting a 478-bp region was performed using 60 BPV sequences from Turkey and other geographical regions of the world. These additional sequences were taken from GenBank. Phylogenetic analyses were created the -MEGA X (Tamura 1992; Kumar et al. 2018) with Maximum likelihood trees based on the Tamura-Nei parameter (TN93+G+I) model (Nei and Kumar 2000; Kumar et al. 2018) with 1,000 bootstrap replicates for the determination of genetic distances between nucleotide sequences.

\section{Histopathologic Method}

For histopathological examination, tissue samples fixed in $10 \%$ formaldehyde solution. After 2-day fixation, tissue samples were passed through alcohol and xylol series for routine tissue processing 
procedure, and then blocked in paraffin. Serial sections of $5 \mu \mathrm{m}$ thickness were taken on a microtome. Slides, which were left to dry for one day, stained with hematoxylin and eosin (H\&E) and examined under a light microscope (Olympus Co., Japan).

\section{Immunohistochemical Method (IHC)}

Sections taken on polylysined slides for the immunohistochemistry the streptavidin-biotin peroxidase complex method were used. BPV antibody [Anti-HPV antibody (BPV-1/1H8+CAMVIR) (ab2417), 1/50 dilution] was used as primary antibody. Mouse and Rabbit Specific HRP/DAB IHC detection kit-micropolymer (ab236466) (Abcam, Cambridge, England) was used as secondary kit. For

immunohistochemistry after deparaffinization and dehydration sections were processed according the manufacturer instruction. Sections incubated $60 \mathrm{~min}$ with primary antibody and antibody dilution solution was used instead of primary antibody for negative controls. Then sections dehydrated by passing through alcohol series, cleared in xylol, cover slipped and evaluated under a light microscope (Olympus CX41). Microphotography and morphometric analysis were performed using the Database Manual Cell Sens Life Science Imaging Software System (Olympus Corporation, Tokyo, Japan).

\section{Transmission Electron Microscopy (TEM)}

Ultrastructural examination was performed on the samples in which the presence of BPV in teat lesions. For this method, the samples were fixed in $2.5 \%$ glutaraldehyde containing $0.1 \mathrm{M}$ phosphate buffer for 24 hours at $4^{\circ} \mathrm{C}$ and then washed 3 times for 15 minutes with phosphate buffer solution (PBS). Then, secondary fixation was provided in $1 \%$ osmium tetroxide containing $0.1 \mathrm{M} \mathrm{PBS}$, at room temperature and in the rotator for 2 hours, and then the tissues were washed again with buffer 3 times. In order to dehydration, the samples were passed through ethyl alcohol series at increasing degrees and at $4{ }^{\circ} \mathrm{C}$ twice for certain times (30\%, 50\%, 70\%, 90\%, 96\%, 100\% (final washing and post-treatments). Tissues cleared in propylene oxide (room temperature) and propylene oxide for 30 minutes (twice). Then, kept in the rotator containing 1/1 ratio of propylene oxide-araldite mixture for 2 hours, the tissues taken in pure araldite were kept in the rotator overnight and buried in araldite at $60^{\circ} \mathrm{C}$ the next day. The resulting blocks were cut at $700 \mathrm{~nm}$ thickness by an ultramicrotome (Leica Ultracut R) and stained with toluidine blue, and the surface parts that were likely to be biofilm were examined under a light microscope (Olympus BX50). Fully thin sections of $60 \mathrm{~nm}$ were taken, which were then coated on 300 mesh copper grids and stained with uranyl acetate-lead citrate. Then sections were examined in TEM of JEOL JEM 1220 brand and model.

\section{Results}

\section{PCR, sequencing and phylogenetic analysis}

At the end of PCR applications carried out using MY09 / MY11 degenerate primer set, no positivity was detected in any of the samples while as a result of PCR applications carried out using FAP59 / FAP64 degenerate primer set, seven BPV strains were isolated and named as Turkey_BUR1_Teat_BPV, 
Turkey_BUR2_Teat_BPV, Turkey_BUR3_Teat_BPV, Turkey_BUR4_Teat_BPV, Turkey_BUR5_Teat_BPV, Turkey_BUR6_Teat_BPV, Turkey_BUR7_Teat_BPV. For the aim of typing the isolates, BPV type specific primers, BPV-1 (L1), 2 (L1), 3 (L1), 4 (E7), 5 (L1), 6 (L1), 8 (L1), 9 (L1), 10 (L1), 11 (L1), 12 (L1), 13 (L1), 13 (E5) and 14 (L1) were used (Table 1). As a result of this application, distribution of types was determined as three BPV-6 (Turkey_BUR2_Teat_BPV, Turkey_BUR4_Teat_BPV, Turkey_BUR7_Teat_BPV), two BPV-10 (Turkey_BUR1_Teat_BPV, Turkey_BUR5_Teat_BPV), one BPV-8 (Turkey_BUR6_Teat_BPV) and one BPV-2 (Turkey_BUR3_Teat_BPV). The sequences reported in this paper were submitted to the GenBank, with accession numbers as follows, Turkey_BUR2_Teat_BPV MZ265290, Turkey_BUR4_Teat_BPV

MZ265291, Turkey_BUR7_Teat_BPV MZ265292, Turkey_BUR1_Teat_BPV

MZ265293, Turkey_BUR5_Teat_BPV MZ265294, Turkey_BUR6_Teat_BPV

MZ265295, Turkey_BUR3_Teat_BPV MZ265296.

The phylogenetic closeness of the isolates to each other obtained in the study has been shown in Table 2 and the phylogenetic tree showing the genetic closeness of the obtained strains to other strains obtained all around the world has been given in Figure 1.

\section{Histopathological Findings}

Both papillomas and fibropapillomas were diagnosed in examined tissues. In papilloma cases, the epidermis and keratin layer were markedly thickened. Acanthotic cells with nuclei were found in the keratin layer, acanthosis and parakeratosis were prominent in epidermis. Spongiosis and ballooning degenerations were frequently observed in the epidermal cells. In many cases, basophilic inclusion bodies were also noted in the cytoplasms of these cells. Erosion and ulcers in the epidermis were commonly observed, especially in large masses because of the trauma. Inflammatory cell infiltrations, mostly mononuclear cells composed of small number of neutrophil leukocytes were noticed in these regions. In addition, bacterial clusters were common findings in the masses with erosion and ulcer. The number and size of keratohyalin granules increased in keratinocytes in papillomas. In the cells of the stratum spinosum and granulosum, koilocytes with large cytoplasmic vacuoles and excentric hyperchromatic nuclei were frequently encountered. In many cases, intense pigmentation was observed in the basal layer. Severe proliferations in the dermis and 'rete pegs' formations were observed. The fibrous connective tissue of the masses, mostly composed of fibroblast and collagen fibers. An increase in mitotic activity was also noted in the masses. Hemorrhages and increased vascularization were observed in most of the masses. In some cases, excessive proliferations were observed in the dermis together with the epidermis, and such cases were evaluated as fibropapilloma (Figure 2).

\section{Immunohistochemical Findings}

BPV positive immunoreaction was observed in the cells of the epidermis. Positive PBV expressions were also detected in the keratinocytes of keratin layer and in the capillary vessels in the dermis (Figure 3).

\section{Transmission Electron Microscopy (TEM) Findings}


Viral agents were detected by ultrastructural examinations in teat papilloma lesions. BPV particles were intracytoplasmic and/or intranuclearly localized in the epithelial cells (Figure 4).

\section{Discussion}

BPV is a viral agent forming benign lesions within cutaneous or mucosa epitheliums in different areas of the body (Maclachan et al. 2017). Cutaneous lesions have different morphologies such as filiform, peduncle, atypical or squamous (Lunardi et al. 2013; Daudt et al. 2018). On the other hand, the virus causes carcinomas in vesicaurinaria, genital and gastrointestinal channel mucosas (Borzacchiello and Roperto 2008; Lunardi et al. 2013; Roperto et al. 2013).

The agent causes full-scale economical losses leading to lesions of various size and structure in animals such as goats, cattle and sheep grown for milk and meat production (Tan et al. 2012; Araldi et al. 2017; Daudt et al. 2018). Papillomas appearing on teats of animals especially in milker herds makes milking impossible and decreases production (Campo 2002). In addition, injuries appearing on teat skin dependent on papillomatosis might make the area predisposed against secondary infections or might cause mastitis (Campo 2002; Zhu et al. 2019).

Detection of papillomaviruses could be done molecularly by using degenerate primers (FAP59/FAP65 MY09/MY11) designed for gene areas coding L1, L2, E6 and E7 proteins (Ogawa et al. 2004). In samples of cutaneous papillomatosis, during the studies carried out for molecular detection of BPV using FAP59/FAP64 degenerate primers, the rate of prevalence was found as between 54-100\% (Ogawa et al. 2004; Silva et al. 2013a; Dağalp et al. 2017). In this study that we carried out using FAP59/64 degenerate primers, viral genome detection was performed in all teat papilloma samples $(100 \%)$. This result is such as to support the results obtained from other studies. No positivity was detected in the samples using the other degenerate primer set. During the studies, Silva et al. (2013b) stated that BPV type specific primers were more sensitive than degenerate primers and degenerate primers fail the recognize in papilloma samples with mixed types. Silva et al. (2013a) found that the specifity of FAP59/64 and MY09/MY11 degenerate primers was lower than type specific primers, it couldn't detect some viral types (for example BPV-4, 9) and the reason for this was that it was designed for human papillomavirus identification (HPV). The difference in BPV infection prevalence is believed to have occurred for these reasons.

Sequencing analysis was performed on L1 gene PCR products amplified from the collected samples and revealed that there were four types of BPV (BPV-2, BPV-6, BPV-8 and BPV-10). Nucleotide similarities of $\mathrm{BPV}$ isolates detected in teat tissue in this study are shown in Table 2. The phylogenetic analysis conducted using the coding sequence of the L1 gene revealed that the tree was divided into five main groups; Xipapillomavirus 1, Dyoxypapillomavirus 1, Epsilonpapillomavirus 1, Deltapapillomavirus and new putative papillomavirus. Five of the nucleotide sequences isolated in this study, (Turkey_BUR1_Teat_BPV, Turkey_BUR2_Teat_BPV, Turkey_BUR4_Teat_BPV, Turkey_BUR5_Teat_BPV, Turkey_BUR7_Teat_BPV) clustered into the Xipapillomavirus 1, Turkey_BUR6_Teat_BPV clustered into the Epsilonpapillomavirus 1, Turkey_BUR3_Teat_BPV clustered into the Deltapapillomavirus (Figure 1). 
According to the phylogenetic tree constructed, BPV isolates were not grouped according to the geographic distribution. At the end of phylogenetic analysis, the obtained isolates showed genetic closeness to those obtained in Brazil, Turkey, Croatia and China.

In previous studies on the histopathological examination of papilloma cases; acanthosis, hyperplasia of the spinal epithelial layer, koilocytosis, hypergranulosis, hyperkeratosis, parakeratosis, papillomatosis, transformed fibroblasts and vacuolar degenerations of the stratum spinosum of the dermis have been reported (Anjos et al. 2010; Marins and Ferreira 2011; Tan et al. 2012; Timurkan and Alcigir 2017). While hyperkeratosis and acanthosis are common findings in papilloma cases, in addition to epidermal proliferations increased connective tissue mainly fibroblasts are the main basic findings in fibropapillomas (Scagliarini et al. 2016). In histopathological studies on teat papillomas of BPV, Jelinek and Tachezy (2005) encountered fibropapillomas containing many koilocytes, neoplastic fibroblasts in the dermis, and acanthosis and orthokeratotic hyperkeratosis in the epidermis. Maeda et al. (2007) identified structures characterized by epithelial hyperplasia, acanthosis and hyperkeratosis, but they could not detect fibropapilloma. Hatama et al. (2009) found epidermis hyperplasias with hyperkeratosis and marked acanthosis. Hatama (2012) stated that they observed epithelial hyperproliferation with normal dermal appearance. Beytut (2017), on the other hand, observed widespread epidermal hyperplasia, acanthosis and hyperkeratosis, as well as an increase in connective tissue in the dermis. However, koilocytes have seen balloon-like degeneration, pycnotic and nuclear fragmentation containing dense chromatin. In this study, our histopathological examination findings, which we mentioned in detail above, in teat lesions were similar to the results of other researchers. At the histopathological examination, proliferations were observed in the epidermis and dermis, in fibropapilloma cases while only epidermal proliferations together with excessively thickened in the keratin layer notices in papilloma cases. Acanthosis and parakeratosis were evident in the keratin layer. Spongiosis and degenerations were frequently observed in the squamous cells of the epidermis. Koilocytes were frequently seen in the stratum spinosum and granulosum. Rete peg formations characterized by severe proliferations in to the dermis towards the epidermis were common findings. The connective tissue which mostly composed of fibroblast and collagen fiber bundles, extended in different directions. In some cases, marked proliferations were observed in the dermis, and such cases were evaluated as fibropapilloma.

In our study, positive immunoreactions were observed in the epidermis and keratin layer in the sections immunohistochemically stained with BPV antibody. In a few cases, a positive reaction was also detected in the capillaries of the dermis. In previous studies, intranuclear or cytoplasmic antigen-antibody reaction was revealed by immunohistochemical method in basophilic intranuclear inclusion bodies in the stratum granulosum layer of the epidermis, endothelial cells of vessels, mesenchymal, horny and granular cells and corneal layer in papilloma cases (Jelinek and Tachezy 2005; Maeda et al. 2007; Catroxo et al. 2013; Beytut 2017; Babu et al. 2020). In fibropapillomas, they reported that positive reactions in the cytoplasm of fibroblasts in the dermis, in different layers of the epidermis, and in the cell nuclei of the basal layer and nuclei around the blood vessels (Jelinek and Tachezy 2005; Maeda et al. 2007). In our study, findings and results determined by immunohistochemical diagnosis in teat papillomas were in parallel with the results of the other researchers. 
In the previous studies, the detection rate of viral agents by electron microscopy was between $0-100 \%$ was reported. Many researchers (Brobst and Hinsman 1966; Pulley et al. 1974; Taichman and LaPorta 1987) stated that BPV first settles in the cell nuclei of the cells of stratum spinosum layer of the epidermis. They caused degeneration at the nuclei of the cells in the stratum granulosum and stratum corneum, and remaining viruses spread. In addition, PVs can only do vegetative replication in epithelial cells, progeny virus cannot be obtained in fibroblasts, and therefore ends with biological death. It was concluded that this difference in prevalence values was due to the fact that the researchers examined the regions other than the areas where the agent replicated, or they tried to detect the virus before the spread of the progeny viruses. In this study, the presence of virus was detected in all lesions as a result of electron microscopical examinations performed on the samples of teat papilloma lesions selected from the positive cases with BPV type specific primers.

\section{Conclusion}

As a result, in this study, serotypes of BPV causing teat papillomas in cattle were detected. In order to provide BPV identification molecularly, consensus primers were to be used before specific primers, which would then prevent loss of time and material. In diagnosis of the agent in teat lesions depending on BPV infection, PCR, histopathology, immunohistochemistry and electron microscopy applications were parallel to one another. It would be useful to take biosafety measures in cattle breeding, to search for factors causing the teat tissue to be predisposed for BPV infection, to detect the most common BPV types and to develop standard commercial vaccines for teat papillomas for these types.

\section{Declarations}

\section{Author contribution}

$Y Y$ and $M K$ conceived and designed research. MK, AU, and SS conducted experiments. MK, ÖÖ, SH, AK and $A U$ contributed new reagents or analytical tools. YY and AAC analyzed data. YY, AAC and AK wrote the manuscript. All authors read and approved the manuscript.

\section{Data availability}

Not applicable

Code availability

Not applicable

\section{Funding}

The authors did not receive support from any organization for the submitted work.

\section{Ethics approval}


Approval was obtained from the animal testing local ethics committee of University Burdur Mehmet Akif Ersoy. The procedures used in this study adhere to the tenets of the Declaration of Helsinki.

\section{Consent to participate}

Not applicable

\section{Consent for publication}

Not applicable

\section{Conflicts of interest}

The authors have no relevant financial or non-financial interests to disclose.

\section{Reference}

1. Altschul SF, Gish W, Miller W, Myers EW, Lipman DJ (1990) Basic local alignment search tool. J Mol Biol 215: 403-410. https://doi.org/10.1016/S0022-2836(05)80360-2

2. Anjos BL, Silva MS, Diefenbach A, Brito MF, Seppa GS, Brum MCS (2010) Sarcoide equino associado ao papilomavírus bovino BR-UEL-4. Ciênc Rural 40: 1456-1459. https://doi.org/10.1590/S010384782010000600037

3. Araldi RP, Assaf SMR, De Carvalho RF, Caldas MA, De Carvalho R, De Souza JM, Magnelli RF, Modolo DG, Roperto FP, Stocco RC, Beçak W (2017) Papillomaviruses: a systematic review. Genet Mol 40(1): 1-21. https://doi.org/10.1590/1678-4685-GMB-2016-0128

4. Babu M, Veena P, Kumar R, Amaravathi P, Vani G, Reddy K (2020) Clinical studies on Bovine Papillomatosis. Int J Livest Res 10: 98-103. http://dx.doi.org/10.5455/ijlr.20200505035011

5. Beytut E (2017) Pathological and immunohistochemical evaluation of skin and teat papillomas in cattle. Turkish J Vet Anim Sci 41: 204-

212. https://dergipark.org.tr/tr/pub/tbtkveterinary/issue/39327/463521

6. Borzacchiello G, Roperto F (2008) Bovine papillomaviruses, papillomas and cancer in cattle. Vet Res 39: 1. https://doi.org/10.1051/vetres:2008022

7. Brobst D, Hinsman EJ (1966) Electron microscopy of the bovine cutaneous papilloma. Vet Pathol 3: 196-207. https://doi.org/10.1177/030098586600300304

8. Campo MS (2002) Animal models of papillomavirus pathogenesis. Virus Res 89: 249226. https://doi.org/10.1016/S0168-1702(02)00193-4

9. Catroxo M, Martins A, Petrella S, Souza F, Nastari B (2013) Ultrastructural study of bovine papillomavirus during outbreaks in Brazil. Int J Morphol 31: 777784. http://dx.doi.org/10.4067/S0717-95022013000200068

10. Dağalp SB, Dogan F, Farzani TA, Salar S, Bastan A (2017) The genetic diversity of bovine papillomaviruses (BPV) from different papillomatosis cases in dairy cows in Turkey. Arch Virol 162: 
1507-1518. https://doi.org/10.1007/s00705-017-3258-8

11. Daudt C, Da Silva FR, Cibulski SP, Streck AF, Laurie RE, Munday JS, Canal CW (2019) Bovine papillomavirus 24: a novel member of the genus Xipapillomavirus detected in the Amazon region. Arch Virol 164: 637-641. https://doi.org/10.1007/s00705-018-4092-3

12. Daudt C, Da Silva FRC, Lunardi M, Alves CBDT, Weber MN, Cibulski SP, Alfleri AF, Alfleri AA, Canal CW (2018) Papillomaviruses in Ruminants: An update. Transbound Emerg Dis 65: 13811395. https://doi.org/10.1111/tbed.12868

13. Dörttaş SD, Dağalp BS (2020) Veteriner hekimlikte papillomaviruslar ve önemi. Atatürk Üniv Vet Bil Derg 15(1): 91-99. https://doi.org/10.17094/ataunivbd.651002

14. Hatama S (2012) Cutaneous papillomatosis in cattle. J Disaster Res 7: 319322. https://doi.org/10.20965/jdr.2012.p0319

15. Hatama S, Nishida T, Kadota K, Uchida I, Kanno T (2009) Bovine papillomavirus type 9 induces epithelial papillomas on the teat skin of heifers. Vet Microbiol 136: 347-351. https://doi.org/10.1016/j.vetmic.2008.11.003

16. Jelinek F, Tachezy R (2005) Cutaneous papillomatosis in cattle. J Comp Pathol 132: 7081 https://doi.org/10.1016/j.jcpa.2004.07.001

17. Kumar S, Stecher G, Li M, Knyaz C, Tamura K (2018) MEGA X: Molecular Evolutionary Genetics Analysis across computing platforms. Mol Biol Evol 35: 15471549. https://doi.org/10.1093/molbev/msy096

18. Lunardi M, Alfieri AA, Otonel RAA, Alfieri AF (2013) Current Issues in Molecular Virology. Viral Genetics and Biotechnological Application. In: Romanowski V (Ed) Bovine PapillomavirusesTaxonomy and Genetic. Intechopen, London, pp 113. https://www.intechopen.com/chapters/44804

19. MacLachlan NJ, Dubovi EJ, Barthold SW, Swayne DE, Winton JR (2017) Fenner's Veterinary Virology, $5^{\text {th }}$ edition. In: Maclachlan NJ, Dubovi EJ (Eds) Papillomaviridae and Polyomaviridae. Elsevier Inc, San Diego, pp 327-356. https://doi.org/10.1016/B978-0-12-800946-8.00011-8

20. Maeda Y, Shibahara T, Wada Y, Kadota K, Kanno T, Uchida I, Hatama S (2007) An outbreak of teat papillomatosis in cattle caused by bovine papilloma virus (BPV) type 6 and unclassified BPVs. Vet Microbiol, 121: 242-248. https://doi.org/10.1016/j.vetmic.2006.12.015

21. Marins RSQS, Ferreira CEP (2020) Clinicopathological and epithelial regression study in cutaneous warts of bovines infected by papillomavirus. Int J Pharm Pharmacol 9(6): 1-5. https://www.internationalscholarsjournals.com/articles/clinicopathologic-and-epithelial-regressionstudy-in-cutaneous-warts-of-bovines-infected-by-papillomavirus.pdf

22. Nei M, Kumar S (2000) Molecular Evolution and Phylogenetics. Oxford University Press, New York

23. Ogawa T, Tomita Y, Okada M (2004) Broad-spectrum detection of papillomaviruses in bovine teat papillomas and healthy teat skin. J Gen Virol 85: 2191-2197. https://doi.org/10.1099/vir.0.80086-0

24. Papillomavirus Episteme (2021): Papillomavirus knowledge source. 10.11.2021. https://pave.niaid.nih.gov/ 
25. Pulley LT, Shively JN, Pawlicki JJ (1974) An outbreak of bovine cutaneous fibropapilomatosis following de-horning. The Cornell Vet 64: 427-434. https://pubmed.ncbi.nlm.nih.gov/4367655/

26. Roperto S, Russo V, Ozkul A, Corteggio A, Sepici-Dincel A, Catoi C, Esposito I, Riccardi MG, Urraro C, Luca R, Ceccarelli DM, Longo M, Roperto F (2013) Productive infection of bovine papillomavirus type 2 in the urothelial cells of naturally occurring urinary bladder tumors in cattle and water buffaloes. PLoS ONE 8: e62227. https://doi.org/10.1371/journal.pone.0062227

27. Scagliarini A, Casa G, Trentin B, Gallina L, Savini F, Morent M, Lavazza A, Puleio R, Buttaci C, Cannella V, Purpari G, Di Marco P, Piquemal D, Guercio A (2016) Evidence of zoonotic poxviridae coinfections in clinically diagnosed papillomas using a newly developed mini-array test. J Vet Diag Invest 28: 5964. https://doi.org/10.1177/1040638715614604

28. Silva MA, de Albuquerque BM, Pontes NE, Coutinho LC, Leitao MC, Reis MC, Castro RS, Freitas AC (2013b) Detection and expression of bovine papillomavirus in blood of healthy and papillomatosisaffected cattle. Genet Mol Res 12: 3150-3156. http://dx.doi.org/10.4238/2013.February.28.31

29. Silva MAR, Batista MVA, Pontesa NE, Santosa EUD, Coutinho LCA, Castro RS, Balbinoa VQ, Freitas AC (2013a) Comparison of two PCR strategies for the detection of bovine papillomavirus. J Virol Methods, 192: 55-58. https://doi.org/10.1016/j.jviromet.2013.04.017

30. Silva MAR, Lima RCP, Cordeiro MN, Borzacchiello G, Freitas AC (2016) Molecular Detection of Animal Viral Pathogens Bovine Papillomavirus. In: Dongyou L (Ed) CRC Press, Florida, pp 727-734.

31. Taichman LB, Breitburd F, Croissant O, Orth G (1984) The Search for a Culture System for Papillomavirus. J Invest Dermatol 83: 2-6. https://doi.org/10.1038/jid.1984.12

32. Tamura K (1992) Estimation of the number of nucleotide substitutions when there are strong transition-transversion and G + C-content biase. Mol Biol Evol 9: 678687. https://doi.org/10.1093/oxfordjournals.molbev.a040752

33. Tan MT, Yildirim Y, Sözmen M, Dağalp SB, Yılmaz V, Kırmızıgül AH, Gökçe E (2012) A histopathological, immunohistochemical and molecular study of cutaneous bovine papillomatosis. Kafkas Uni Vet Fak Derg 18(5): 739-

744. https://vetdergikafkas.org/uploads/pdf/pdf_KVFD_1168.pdf

34. Timurkan MO, Alcigir ME (2017) Phylogenetic analysis of a partial L1 gene from bovine papillomavirus type 1 isolated from naturally occurring papilloma cases in the northwestern region of Turkey. Onderstepoort J Vet Res 84: a1450. https://doi.org/10.4102/ojvr.v84i1.1450

35. Ugochukwu ICI, Aneke Cl, Idoko IS, Sani NA, Amoche AJ, Mshiela WP, Ede RE, ibrahim NDG, Njoku ClO, Sackey AKB (2019) Bovine papilloma: aetiology, pathology, immunology, disease status, diagnosis, control, prevention and treatment: a review. Comp Clin Path 28: 737745. https://doi.org/10.1007/s00580-018-2785-3

36. Walker PJ, Siddell SG, Lefkowitz EJ, Mushegian AR, Dempsey DM, Dutilh BE, Harrach B, Harrison RL, Hendrickson RC, Junglen S, Knowles NJ, Kropinski AM, Krupovic M, Kuhn JH, Nibert M, Rubino L, Sabanadzovic S, Simmonds P, Varsani A, Zerbini FM, Davidson AJ (2019) Changes to virus taxonomy and the International Code of Virus Classification and Nomenclature ratified by the 
International Committee on Taxonomy of Viruses. Arc Virol 164: 24172429. https://doi.org/10.1007/s00705-021-05156-1

37. Zhu W, Yuan D, Norimine J, Gao N, Fan S, Du Y, LI F, Yang M, Hu S, Dong J (2019) Teat papillomatosis in dairy herds: First detection of bovine papillomavirus type 10 in China. J Vet Med Sci 81: 1063-1066. https://doi.org/10.1292/jvms.18-0449

\section{Tables}

Due to technical limitations, tables 1 and 2 are only available as a download in the Supplemental Files section.

Figures 


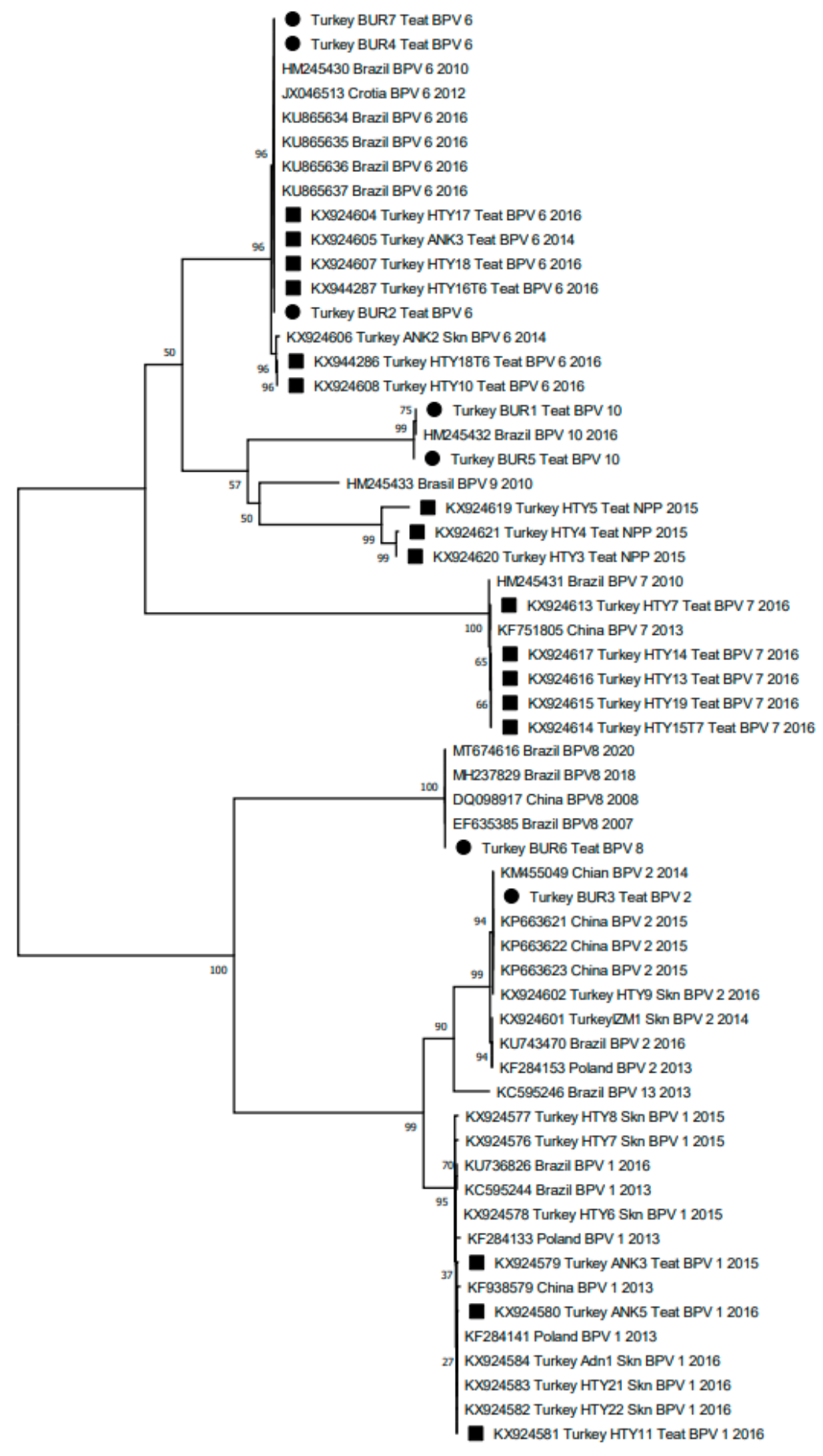

\section{Figure 1}

Phylogenetic tree according to the FAP59/FAP64 primer set 


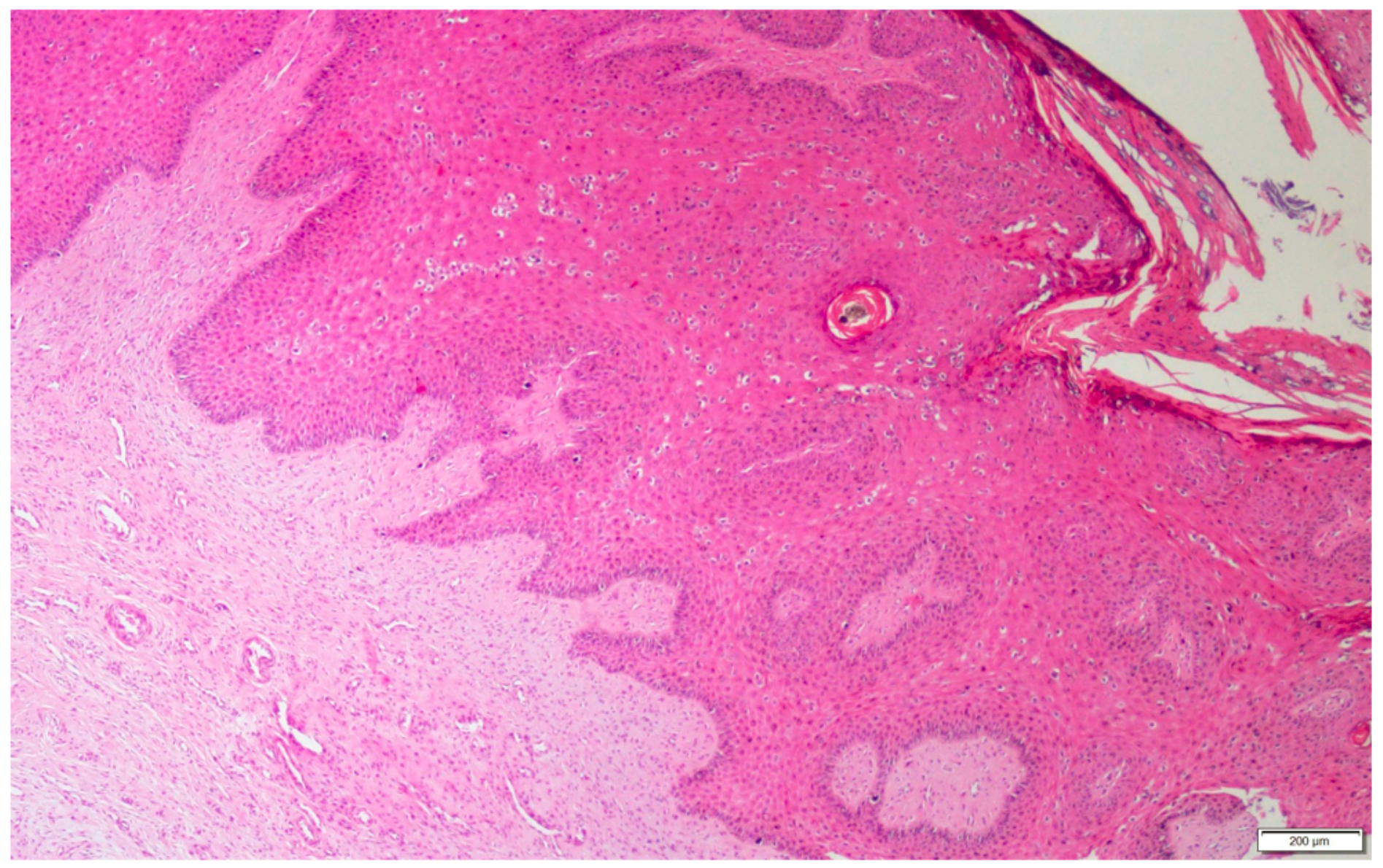

Figure 2

Histopathological examination appearance of a typical papilloma, thickening of the epidermis and keratin layer, $(\mathrm{HE}, \mathrm{Bar}=200 \mu \mathrm{m})$ 


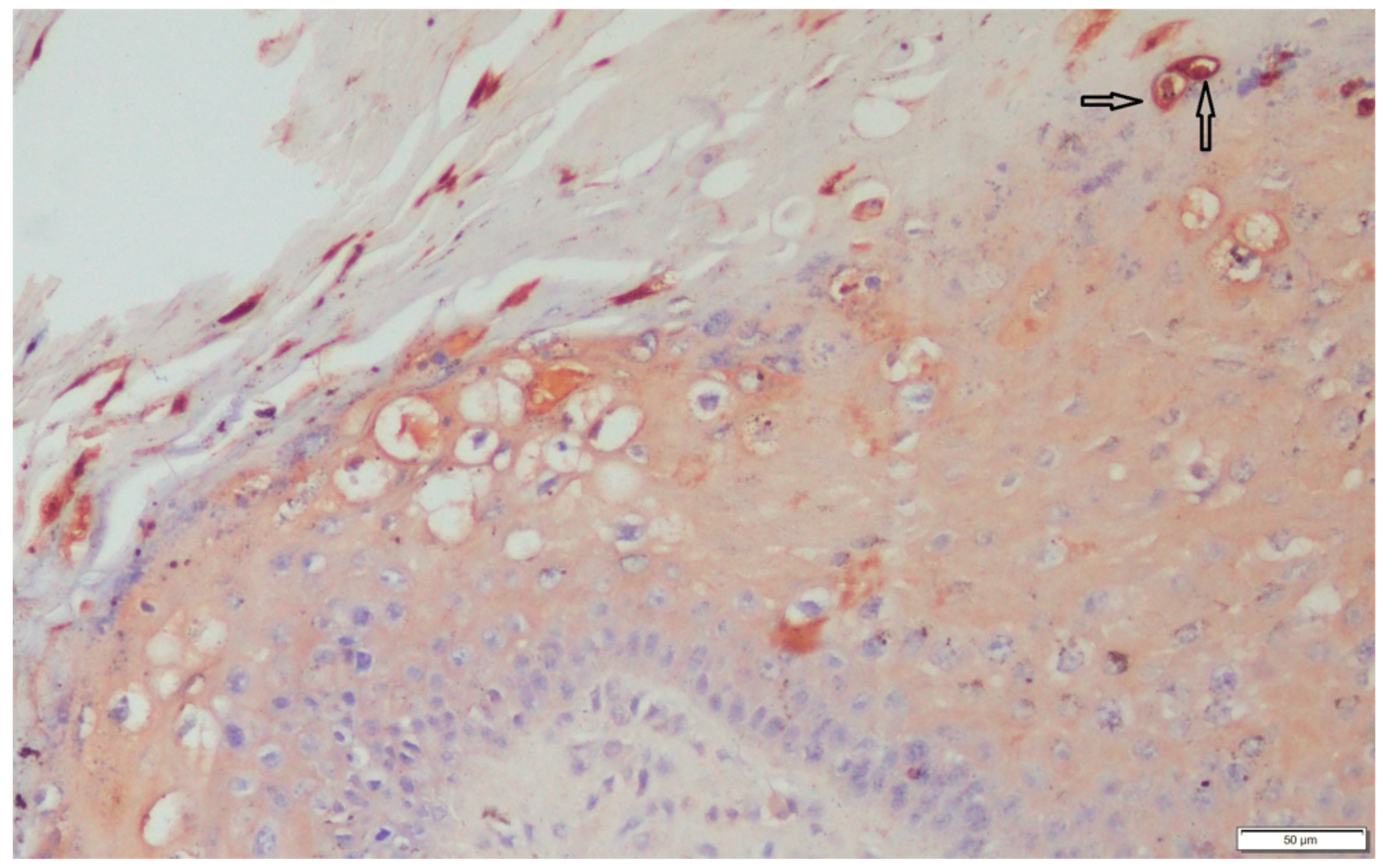

Figure 3

BPV positive immunoreaction (arrows), Streptavidin biotin peroxidase method, (Bar $=50 \mu \mathrm{m})$ 


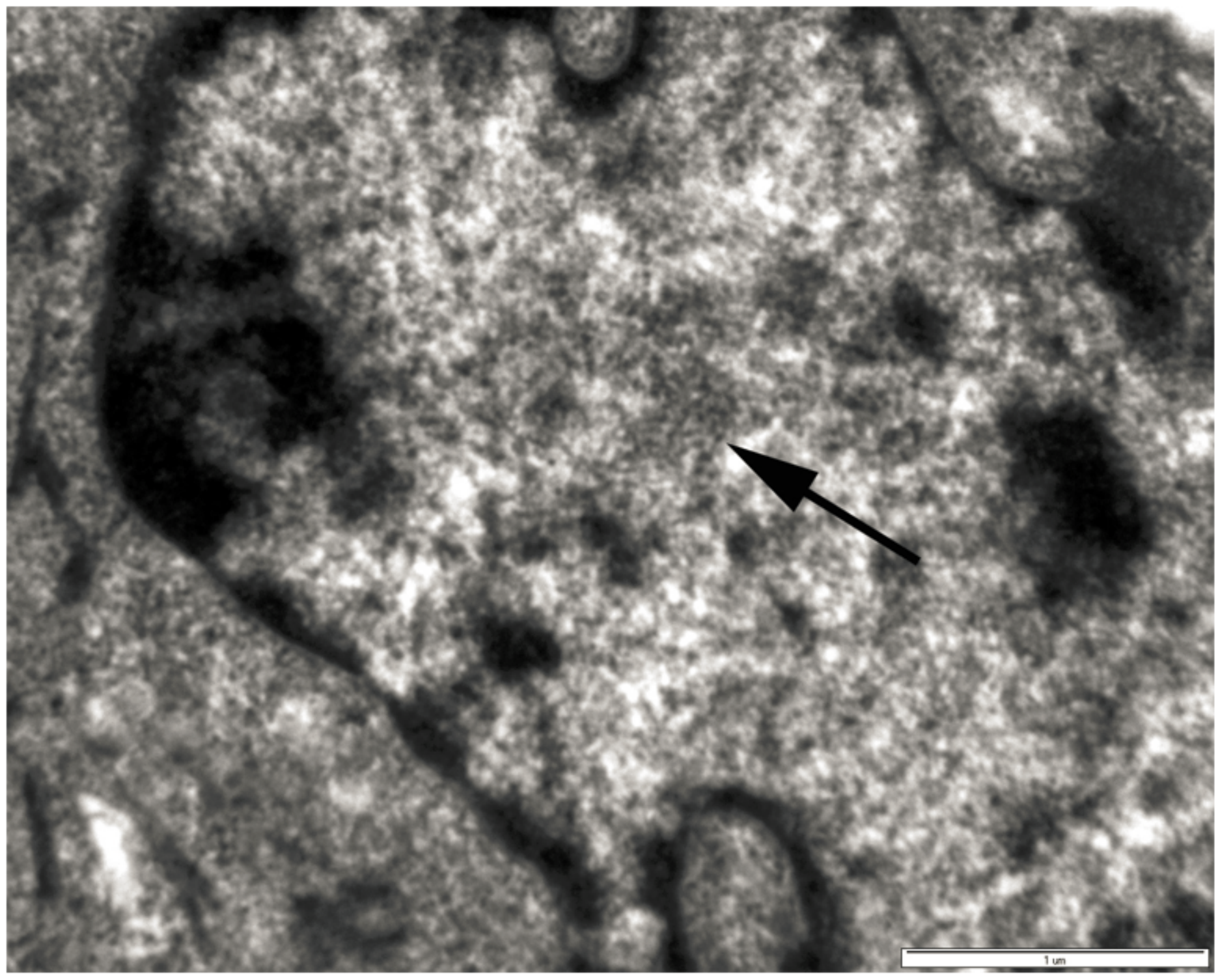

\section{Figure 4}

Transmission electron microscopy view of intranuclear virus particles (arrow) in teat epithelial cells (Bar = $1 \mu \mathrm{m})$

\section{Supplementary Files}

This is a list of supplementary files associated with this preprint. Click to download.

- Table1.Primersused.pdf

- table.2Phylogeneticaffinitiesof.pdf 